\title{
CAVITATION-GENERATED FREE RADICALS DURING SHOCK WAVE EXPOSURE: INVESTIGATIONS WITH CELL-FREE SOLUTIONS AND SUSPENDED CELLS
}

\author{
Dierk SuHr, Franz BrüMmer and DieTer F. Hülser \\ Abteilung Biophysik, Biologisches Institut, Universität Stuttgart, \\ Pfaffenwaldring 57, D-7000 Stuttgart 80, Germany \\ (Received 3 March 1991; in final form 18 July 1991)
}

\begin{abstract}
Extracorporeally generated shock waves as used in lithotripsy of urinary and biliary stones exhibit side effects in vivo. Furthermore, these shock waves destroy eukaryotic cells during in vitro treatment in suspension. A possible cause of these damaging effects might be cavitation, the growth and collapse of bubbles in liquids exposed to tensile stresses. During the collapse, temperature inside these cavitation bubbles rises up to several thousand $\mathrm{K}$, leading to the formation of free radicals. We demonstrated the occurrence of cavitation-generated free radicals by direct reaction with fluorescent dyes in solution after shock wave treatment and investigated the resulting cell killing by variation of the cellular antioxidative defense status. We present evidence for the generation of intracellular free radicals during shock wave treatment of suspended cells.
\end{abstract}

Key Words: Shock waves, Lithotripsy, Cavitation, Free radicals, Cell culture, Scavengers, Superoxide dismutase, Catalase, Fluorescent dyes, Flow cytometry.

\section{INTRODUCTION}

Extracorporeally generated shock waves are used in medicine for the fragmentation of urinary and biliary stones. In vivo side effects of this treatment, like hematuria, tissue injury, and temporary loss of renal function (reviews: Lingeman et al. 1988; Brümmer et al. 1990a) occurred in many cases. Shock waves also destroy eukaryotic cells in a dose-dependent manner when cells were treated in suspension (Russo et al. 1986; Brümmer et al. 1989). One of the mechanisms discussed for stone fragmentation and tissue damage is cavitation (Crum 1988; Delius and Brendel 1988), the formation of gas- or vapour-filled bubbles in liquids exposed to tensile stresses and their violent collapse (Coleman et al. 1987). The high velocity of this breakdown-as the collapse of the bubble walls exceeds the speed of sound-causes an adiabatic compression of the gas inside the bubble without heat exchange with the surrounding medium. This compression results in a local temperature increase in the bubble up to several thousand $\mathrm{K}$. Under these conditions, a homolytic cleavage of molecules may take

Address correspondence to: Dierk Suhr. place, leading to the formation of free radicals, i.e., short-living highly reactive molecules or atoms (Flynn 1982; Edmonds and Sancier 1983; Makino et al. 1983; Crum and Fowlkes 1986).

Former studies dealing with shock waves, cavitation, and free radicals were performed in cell-free solutions or observed the extracellular occurrence of free radicals. This paper presents our results of intraand extracellular in vitro measurements of free radicals using fluorescent dyes as indicators for shock wave induced cavitation. Furthermore, we varied the cellular antioxidative defense status, using extra- and intracellular radical scavengers or inhibitors of radical scavenging enzymes, and investigated cell viability after shock wave treatment under these conditions.

\section{MATERIALS AND METHODS}

MGH-U1 cells, a human bladder carcinoma line, were cultivated as monolayers (Evans et al. 1977; Masters et al. 1986). Cells were grown to subconfluence, and single-cell suspensions $\left(2-3 \cdot 10^{5}\right.$ cells $/ \mathrm{ml}$ in phosphate buffered saline [PBS]) were obtained by a 4 min treatment with trypsin (Serva, Heidelberg, Germany; $0.25 \%$ in PBS) and mechanical dispersion. Variations in cellular antioxidative defense status 
were performed with L1210 cells, a mouse leukemia line (Law et al. 1949; Hutchison et al. 1966). Suspension cultures of L1210 cells were spun down $(10 \mathrm{~s}$, $1,000 \mathrm{~g}$ ) and resuspended in PBS to a final concentration of $2-3 \cdot 10^{5}$ cells $/ \mathrm{mL}$. Cells were maintained at $37^{\circ} \mathrm{C}$ and $8 \% \quad \mathrm{CO}_{2}$ in RPMI 1640 medium (Boehringer Mannheim, Mannheim, Germany), supplemented with $10 \%$ fetal calf serum (Boehringer Mannheim), $24 \mathrm{mM} \mathrm{NaHCO}$, and antibiotics. Culture medium for $\mathrm{L} 1210$ was additionally supplemented with $180 \mu \mathrm{M}$ sodiumpyruvate (Serva) and 5 $\mu \mathrm{M}$ mercaptoethanol (Serva). Single-cell suspensions were transferred into polyethylene pipettes $(4.5 \mathrm{~mL}$, Brand, Wertheim, Germany) and treated with shock waves. The pipette ball was submerged in the partially degassed (2.1-3.3 $\left.\mathrm{mg} \mathrm{O}_{2} / \mathrm{L}\right)$ waterbath of an experimental spark gap lithotripter XL-1 (Dornier Medizintechnik, Germering, Germany) and positioned into the target focus of the brass semi-ellipsoid. Suspended MGH-U1 cells and dye solutions were kept at $21^{\circ} \mathrm{C}$ and exposed to shock waves at a shock wave repetition frequency of 1 or $8 \mathrm{~Hz}$ and a generator voltage setting of $18 \mathrm{kV}$. The dye was protected against the light flash of the electrode by a nontransparent black plastic foil. The foil was fixed on a sloping frame which guided air bubbles out of the path of the shock wave. The cover does not reduce the energy of shock waves (data not shown). In experiments with cells under different antioxidative defense conditions, 250 shock waves $(1 \mathrm{~Hz}, 18 \mathrm{kV})$ were administered to $\mathrm{L} 1210$ cells at a waterbath temperature of $37^{\circ} \mathrm{C}-\mathrm{a}$ dose which represents the $\mathrm{LD}_{50}$ of $\mathrm{L} 1210$ without scavengers or enzyme inhibitors (Brümmer et al. 1990b). Controls were kept in a waterbath at the same temperature and for the same time span as the corresponding shock wave treated probes. Electrodes were not used for experiments prior to the first 50 and after 1500 electrical discharges.

By addition of exogenous scavengers, the cellular damage caused by free radicals can be reduced, whereas the inhibition of endogenous defense enzymes can have the opposite effect. For elevation of the antioxidative defense status, the suspension medium (PBS) was supplemented immediately before treatment with cysteamine or cystamine (Sigma, Deisenhofen, Germany), two scavengers of free radicals (Révész and Bergstrand 1963; Sawada and Okada 1970). We used concentrations from 10 to $50 \mathrm{mM}$. Stock solutions of scavengers were prepared $2 \mathrm{M}$ in PBS.

A possibility to increase the cellular sensitivity to radicals is given by the inhibition of two endogenous enzymes, superoxide dismutase and catalase, which both protect cells from damage by intracellular free radicals. Superoxide dismutase was inhibited by incubating the cells with $3 \mathrm{mM}$ diethyldithiocarbamate (Sigma) for $40 \mathrm{~min}$ at $37^{\circ} \mathrm{C}$, catalase activity was reduced by a treatment with $20 \mathrm{mM}$ aminotriazole (Sigma) for the same time and temperature. For this treatment, a $96 \%$ inhibition of superoxide dismutase and $70 \%$ inhibition of intracellular catalase is reported (Scott et al. 1987).

Viability of cells was determined by combined measurements with a cell counter (Coulter Counter D Industrial, Coulter Electronics, Hialeah, FL, USA) excluding destroyed cells, and a flow cytometer (FACS-Analyzer, Becton-Dickinson, Heidelberg, Germany) using a double staining method for viable and dead cells (Jones and Senft 1985): cells that were able to hydrolyze fluorescein diacetate (FDA) and so exhibit a green fluorescence of fluorescein were considered as viable, while cells whose membrane could not exclude the dye propidium iodide and show a red fluorescence were counted as dead (for details, see Brümmer et al. 1989). Determinations of cell diameters were performed in a FACS-Analyzer, equipped with an electrical resistance pulse sizing following the Coulter principle (Coulter 1956), and using a calibration curve for absolute particle sizes (Brenner and Hülser 1991).

For the detection of free radicals, we used hydroethidine (Polyscience, St. Goar, Germany) and dichlorofluorescin diacetate (DCFH-DA, Serva), two dyes which become fluorescent after oxidation, e.g., by dehydrogenases (Bucana et al. 1986) or by radicals. Hydroethidine was first described in 1972 by Thomas and Roques, DCFH-DA in 1965 by Keston and Brandt. Both dyes have already been used for the detection of radicals during respiratory burst in stimulated leukocytes (Bass et al. 1983; Burow and Valet 1987; Rothe and Valet 1990).

Hydroethidine is trapped inside the cells after oxidation to ethidium which shows a significant increase in fluorescence after intercalation in the DNA (LePecq and Paoletti 1967). The reduced form hydroethidine does not bind to DNA and shows a different fluorescence spectrum than ethidium (Thomas and Roques 1972). DCFH-DA accumulates intracellularly after deacetylation to dichlorofluorescin (DCFH) and becomes fluorescent after oxidation to dichlorofluorescein (DCF). As a control, we used a radical insensitive dye, fluorescein diacetate (FDA, Sigma) which becomes fluorescent after deacetylation without oxidation. The final dye concentration in the suspension was $1 \mu \mathrm{M}$ for DCFH-DA (stock solution $10 \mathrm{mM}$ in dimethylformamid [DMF, Sigma]) and for FDA (stock solution $0.5 \mathrm{mM}$ in acetone) or $16 \mu \mathrm{M}$ for hydroethidine (stock solution $63.5 \mathrm{mM}$ in DMF). For 
shock wave treatment, cell suspensions stained with DCFH-DA or FDA were incubated for $30 \mathrm{~min}$ at $37^{\circ} \mathrm{C}$ in the dark, hydroethidine-stained cells were treated $10 \mathrm{~min}$ after addition of the dye.

To investigate the appearance of extracellular cavitation and radicals, $1 \mu \mathrm{M}$ DCFH-DA or FDA was hydrolyzed to DCFH or fluorescein by incubation for 30 min with carboxyl esterases (Sigma, final activity approx. $1 \mathrm{unit} / \mathrm{mL}$ ) and then treated with shock waves. Hydroethidine was treated with shock waves at a concentration of $160 \mu \mathrm{M}$. This higher concentration was necessary because of the weak fluorescence without intercalation in DNA (LePecq and Paoletti 1967).

The fluorescence of shock wave treated cells and controls was determined by flow cytometry (FACSAnalyzer, Becton-Dickinson). Fluorescence was excited by a high pressure mercury arc lamp (filter: 485 $\pm 22 \mathrm{~nm})$ and detected in fluorescence channel 1 (FL1, $530 \pm 30 \mathrm{~nm}$; DCF and fluorescein) or FL2 $(595 \pm 63 \mathrm{~nm}$; ethidium). In the volume channel (VOL), a gate was set to exclude destroyed cells and debris, so only intact cells were counted. For each cell, the ratio (RTO) between fluorescence (FL1 or FL2) and VOL was determined to eliminate the influence of possible changes in the volume of shock wave treated cells. Per reading, data from 10,000 cells were stored and analyzed in a HP 9133 computer (HewlettPackard Co., Fort Collins, CO, USA) with the Consort 30 version $\mathrm{E}$ software (Becton-Dickinson). The fluorescence of dye solutions was detected with a spectrofluorometer (LS-3B, Perkin-Elmer, Überlingen, Germany). For measurements of DCF and fluorescein, excitation wavelength was set to $495 \mathrm{~nm}$, emission was registered at $525 \mathrm{~nm}$. Ethidium was excited at $473 \mathrm{~nm}$ and fluorescence measured at 593 $\mathrm{nm}$. For each experiment, the change in fluorescence was calculated by dividing the mean of fluorescence of the shock wave treated sample by the mean of fluorescence of the untreated control, and is given as relative fluorescence.

All data are presented as means \pm standard error of the mean. For significance, an error probability $\alpha$ $\leq 0.05$ in the two-sided Mann-Whitney-Wilcoxon Utest was assumed.

\section{RESULTS}

The influence of free radicals after shock wave treatment was tested with exogenous supplied scavengers for both intra- and extracellular reactions. Viability tests have been performed with L 1210 cells, a wellestablished and standardized test system for shock wave efficacy (Brümmer et al. 1990c). When treated with shock waves in the presence of scavengers, more
L1210 cells survived than in controls exposed to shock waves without scavengers. This was found for both cysteamine and cystamine. For the highest concentration of $50 \mathrm{mM}$ about $65 \%(66 \pm 2 \%$ and 64 $\pm 3 \%$, respectively) survived as compared to $48 \pm 1 \%$ for the shock wave treated cells without scavengers (Fig. 1). Since the addition of scavengers had no effect on the viability of L1210 cells without shock wave exposure, but resulted in a reduction of the mean cell diameter ( 11.8 to $11.2 \mu \mathrm{m}$ for cysteamine and 11.8 to $10.2 \mu \mathrm{m}$ for cystamine; Fig. 2), we were unable to

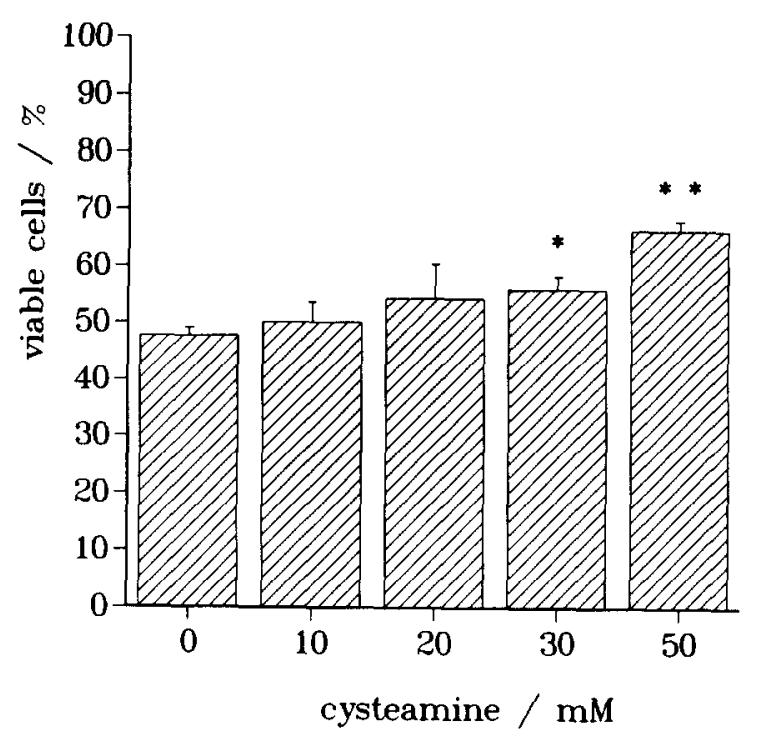

(a)

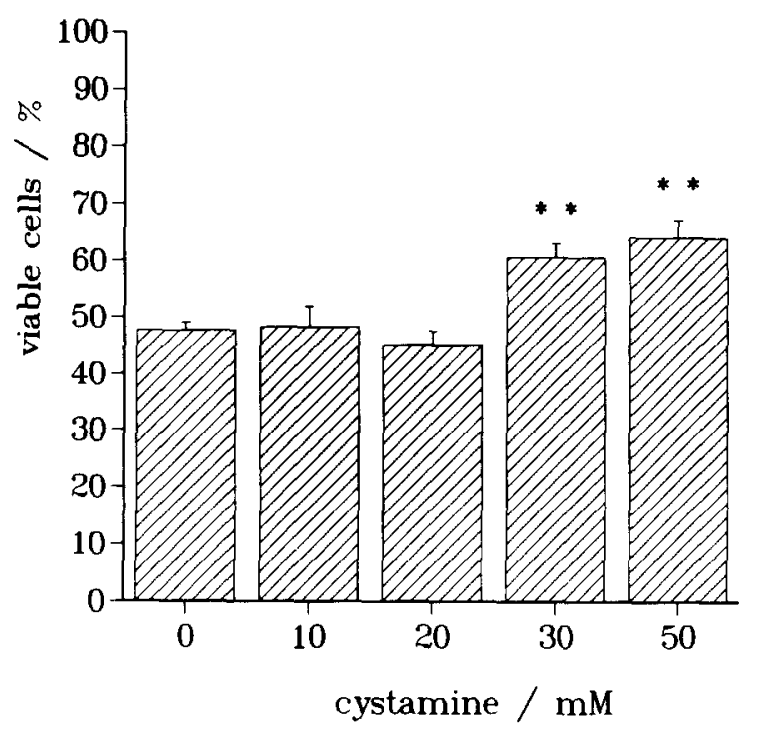

(b)

Fig. 1. Effect of different scavenger concentrations on survival rate of $L 1210$ cells after treatment with 250 shock waves: (a) cysteamine, (b) cystamine. ${ }^{*} \alpha<0.05$ vs. control; ${ }^{* *} \alpha<0.002$ vs. control. 


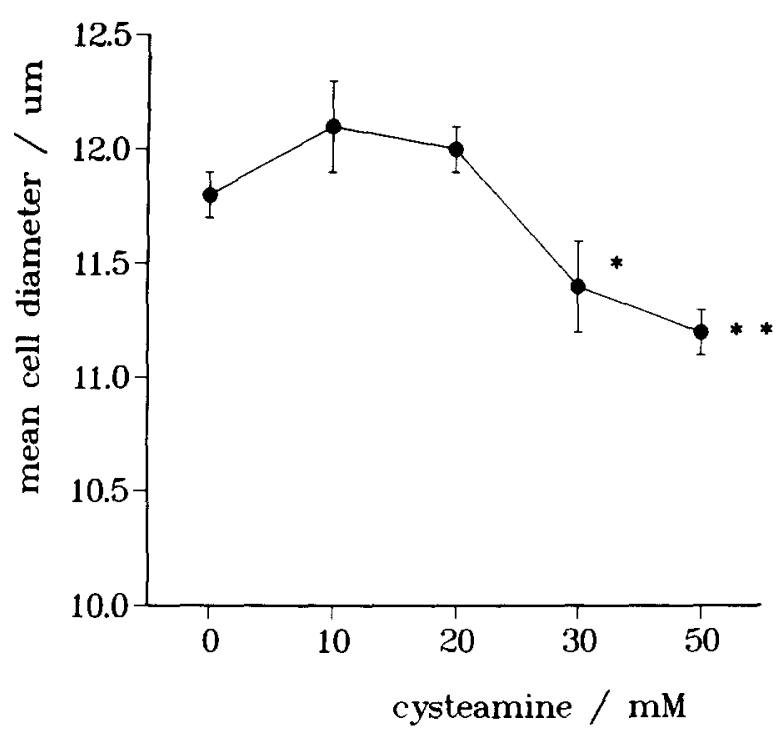

(a)

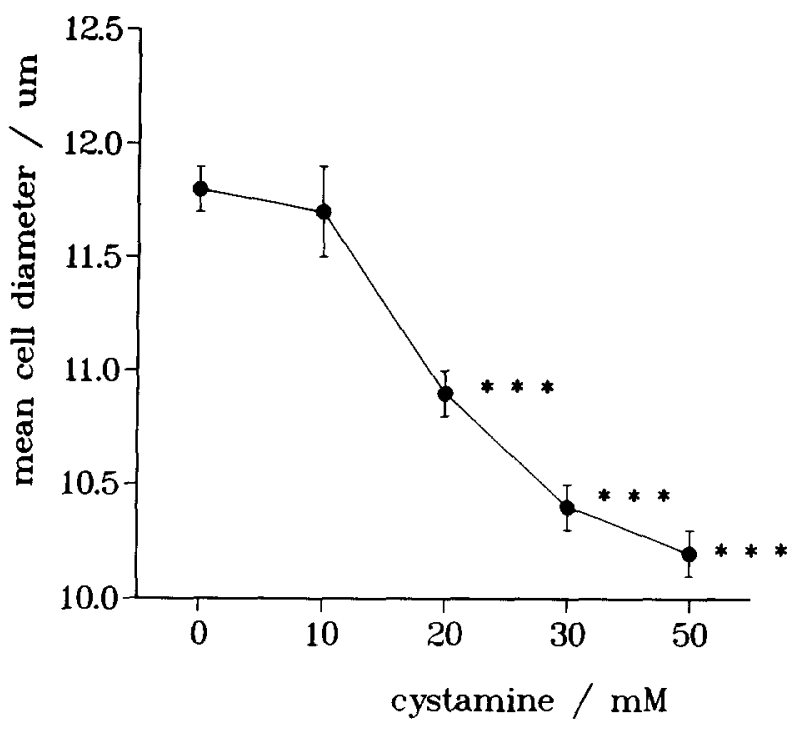

(b)

Fig. 2. Effect of different scavenger concentrations on diameter of L1210 cells: (a) cysteamine, (b) cystamine. ${ }^{*} \alpha<0.05$; ${ }^{* *} \alpha<0.01 ;{ }^{* * *} \alpha<0.001$ vs. control.

distinguish whether the higher survival rate was due to an osmotic effect or to the intended protection.

The influence of free radicals was, therefore, also investigated by inhibiting the endogenous defense enzymes. To reduce the activity of superoxide dismutase and catalase, cells were incubated with diethyldithiocarbamate and aminotriazole. Under these conditions L1210 cells exhibited a higher sensitivity to shock waves than cells not treated with inhibitors (Fig. 3). In contrast to the addition of the scavengers cysteamine and cystamine, the inhibition of defense

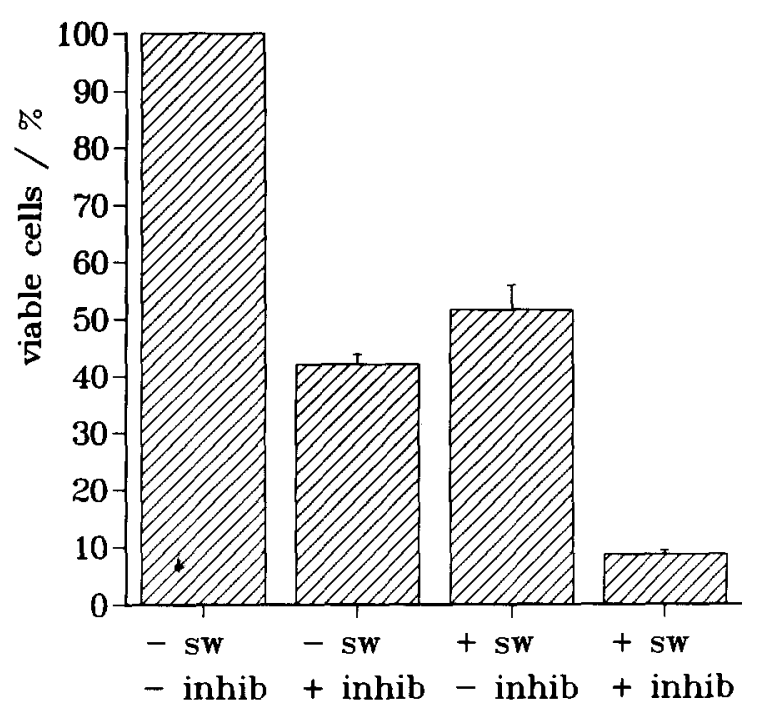

Fig. 3. Viability of L1210 cells after treatment with diethyldithiocarbamate and aminotriazole (inhibitors of the defense enzymes superoxide dismutase and catalase) and shock waves.

enzymes alone showed a considerable decrease in cell viability without shock wave treatment (Fig. 3).

To exclude unspecific reactions of scavengers and/or enzyme inhibitors, which might influence the measured cell viability, we determined free radicals by their direct reaction with dyes that become fluorescent after oxidation. For this purpose the dyes were exposed to shock waves under both cell-free and intracellular conditions. Using cell-free hydroethidine

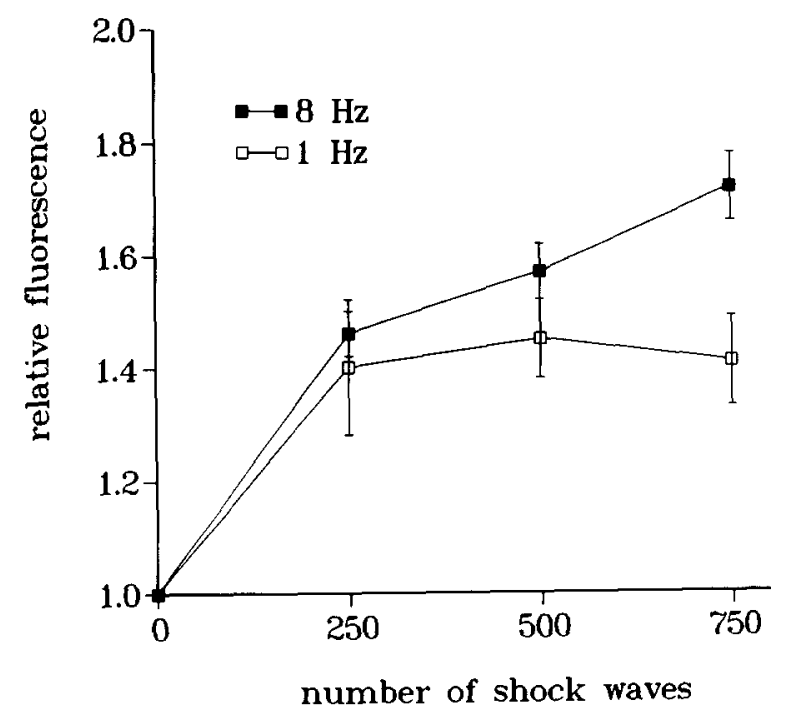

Fig. 4. Production of free radicals by shock waves in cellfree hydroethidine solutions: dose and shock wave repetition frequency dependent increase in red fluorescence of ethidium. 
and DCFH solutions, an increase in fluorescence was measured in a repetition frequency and dose-dependent manner after shock wave treatment (Figs. 4 and 5 ), indicating a production of free radicals. The fluorescence of fluorescein, a radical insensitive dye, remained unaffected even after 500 shock waves at a repetition rate of $8 \mathrm{~Hz}$ (Fig. 5).

Leukocytes can be stimulated to produce oxygen-derived free radicals, called the respiratory burst, after phagocytosis or upon chemical excitation. This mainly holds for granulocytes but also for lymphocytes (Rothe and Valet 1990). Since a stimulation of free radical production in the lymphocyte derived L1210 cells by shock waves or cell debris cannot be excluded, we investigated the intracellular concentration of free radicals by dyes with human bladder cells. Suspended MGH-U1 cells, stained with hydroethidine, revealed a small but significant increase in intracellular ethidium fluorescence after shock wave treatment at $8 \mathrm{~Hz}$ (Fig. 6) as a result of the intercalation of the oxidation product ethidium in the DNA, indicating a dose-dependent increase in intracellular free radicals. Since this increase might be counteracted by dye leakage through transient membrane ruptures, we investigated a permeabilization of the cell membrane with the radical insensitive dye fluorescein. Indeed, its intracellular fluorescence is diminished (Fig. 7), whereas its cell-free fluorescence is unaffected by 500 shock waves (Fig. 5). This indicates a transient permeabilization of MGH-U1 cells which is not only

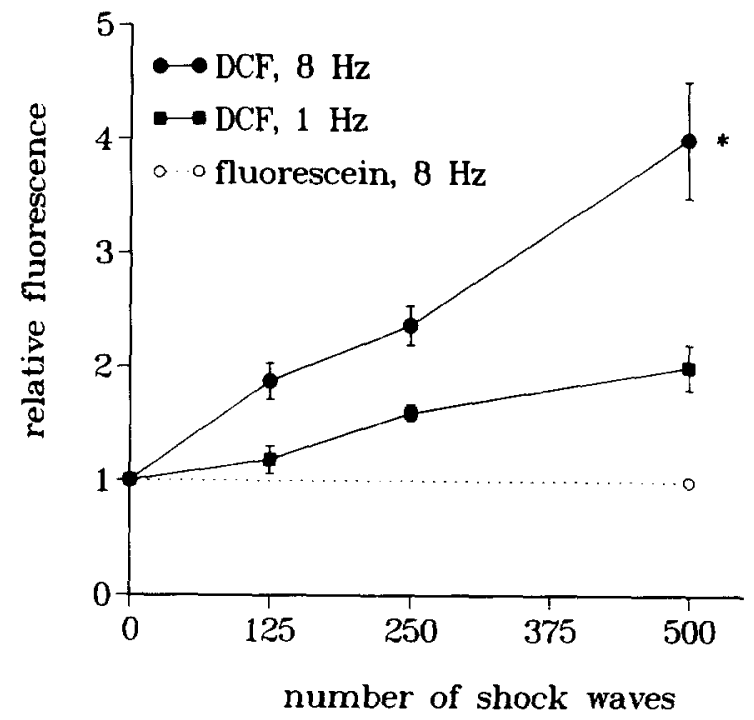

Fig. 5. Production of free radicals by shock waves in cell-free dichlorofluorescin solutions: dose and shock wave repetition frequency dependent increase in green fluorescence of dichlorofluorescein; fluorescence of radical insensitive fluorescein remains unaffected by shock waves. ${ }^{*} \alpha<0.05$ vs. 500 shock waves $/ 1 \mathrm{~Hz}$.

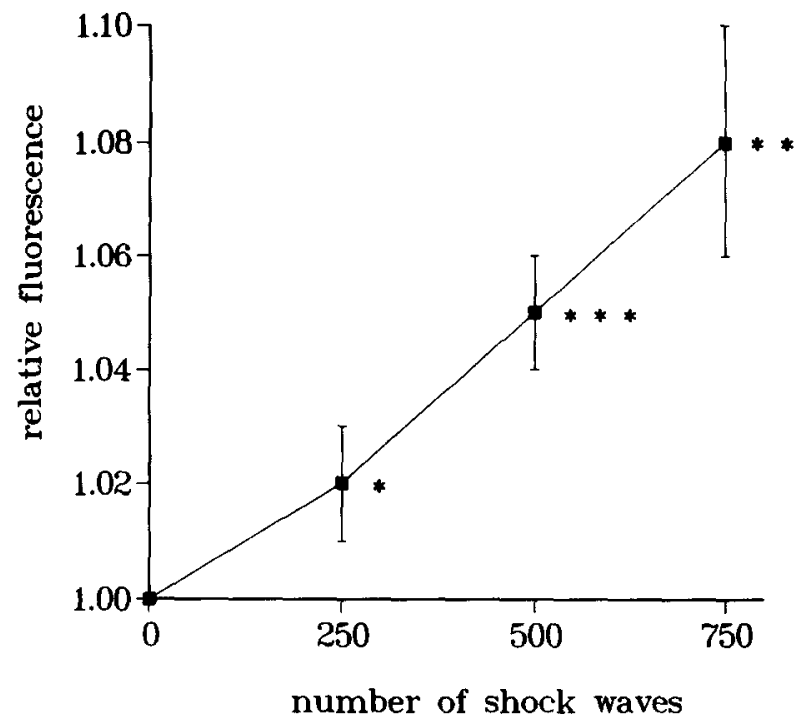

Fig. 6. Production of free radicals by shock waves in MGHU1 cells: dose dependent intracellular increase in red ethidium fluorescence. Shock wave repetition frequency: $8 \mathrm{~Hz}$. ${ }^{*} \alpha<0.05 ;{ }^{* *} \alpha<0.02 ;{ }^{* * *} \alpha<0.01$ vs. control.

dose dependent but also shock wave repetition frequency dependent (Fig. 7). A similar result was obtained with DCFH, which is used for the detection of intracellular free radicals. Since endogenous oxidants and hydrogenases are always present in the cells, untreated controls already show intracellular fluorescence. This fluorescence was reduced with increasing numbers of applied shock waves in spite of the cavitation-generated intracellular free radicals which should add to the intracellular fluorescence. At a shock wave repetition frequency of $1 \mathrm{~Hz}$, the amount of generated free radicals is less than at $8 \mathrm{~Hz}$ (Fig. 5). Thus, the difference in relative fluorescence of the radical-insensitive dye fluorescein and the radical-sensitive dye dichlorofluorescin after treatment at $8 \mathrm{~Hz}$ must be accounted to the shock wave generated intracellular free radicals (Fig. 7).

\section{DISCUSSION}

During shock wave treatment, cavitation might occur in patients and has been discussed in connection with tissue injury (Fischer et al. 1988) and stone fragmentation (Delius and Brendel 1988). Only few publications report about evidence for cavitation in vivo: in piglet liver (Delius et al. 1990) and in dog kidneys (Kuwahara et al. 1990) cavitation bubbles have been traced by ultrasonic imaging; acoustic measurements indicated cavitation events in tumor-bearing rats and mice (Riedlinger et al. 1988) as well as in Beagle dogs (Williams et al. 1989). Acoustic cavitation can generate free radicals in cell-free solutions as 


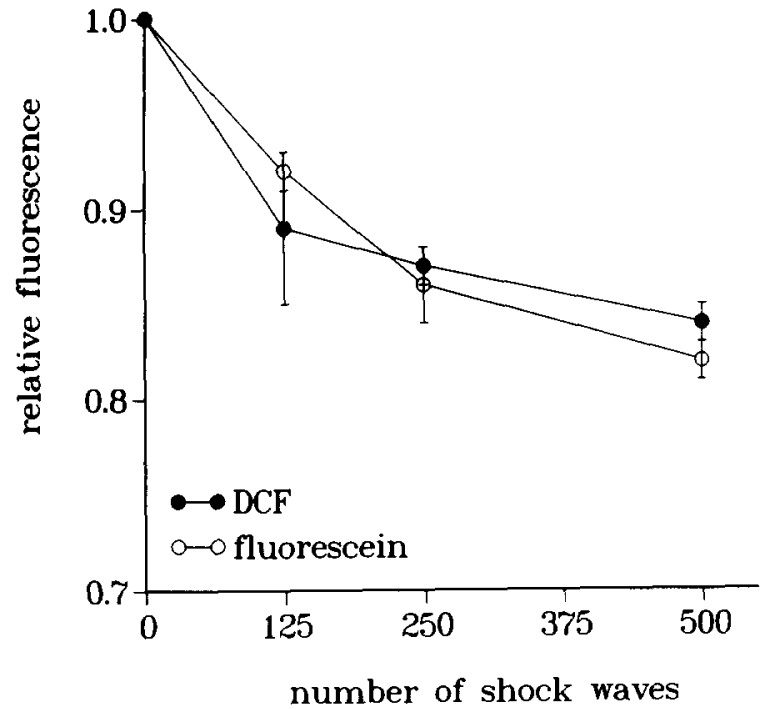

(a)

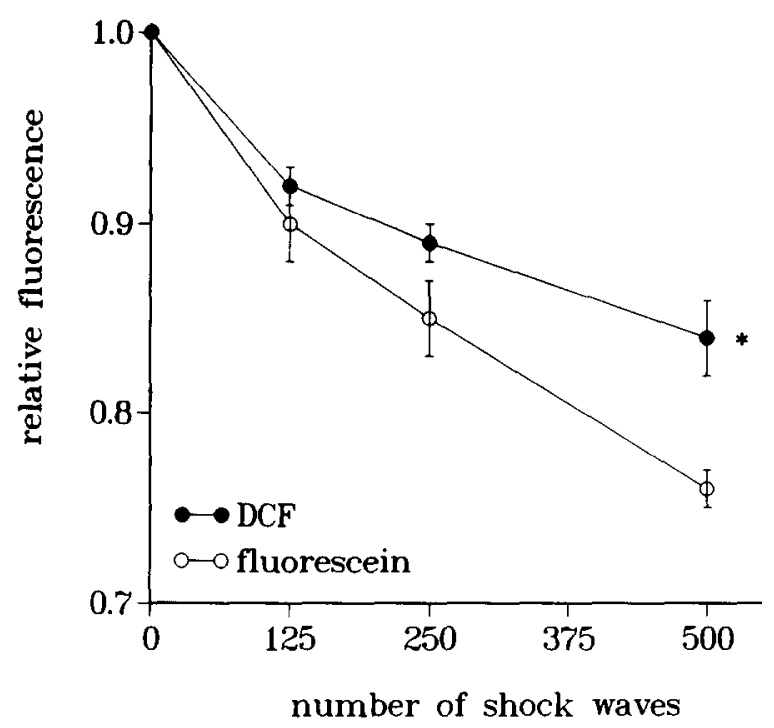

(b)

Fig. 7. Dose and shock wave repetition frequency dependent decrease in intracellular fluorescence in shock wave treated MGH-Ul cells, indicating a dye leakage through transient ruptures of the membranes. Decrease in fluorescein-and DCF-fluorescence after treatment at a shock wave repetition frequency of (a) $1 \mathrm{~Hz}$ and (b) $8 \mathrm{~Hz}$. ${ }^{*} \alpha=0.05$ vs. fluorescein.

has been shown by oxidation of iodide in bursts of a piezoelectric lithotripter (Henglein et al. 1988) or by Fricke dosimetry in a Dornier lithotripter (Morgan et al. 1988). Our experiments allowed a discrimination between intra- and extracellular free radicals upon shock wave exposure and clearly indicated a dose-dependent production of free radicals.

Investigating the extracellular events, we found an increase in fluorescence after shock wave treat- ment of cell-free dye solutions indicating the generation of free radicals which are due to cavitation. Fluorescence of DCFH- or hydroethidine-solutions is multiplied when shock waves are applied to not completely filled pipettes (data not shown). In this case the pressure wave is reflected at the air-liquid interface as a cavitation-generating tensile wave (Morgan et al. 1988). The shock wave repetition frequency dependent increase in fluorescence is attributable to collapsed cavitation bubbles which act as cavitation nuclei with a very short lifetime. With increasing shock wave repetition frequency, therefore, an increasing number of nuclei and more cavitation events are observed (Henglein et al. 1988). Our experiments with dichlorofluorescin and hydroethidine have proven the capability of these dyes to react under shock wave exposure.

Assuming a generation of intracellular cavitation during shock wave treatment, the resulting free radicals can be detected by different strategies, which all are somehow insufficient with regard to unspecific or superimposed reactions of the cells. The first strategy is the addition of exogenous scavengers, which increase the cellular defense status against free radicals by supplementing the endogenous defense enzymes and antioxidants. This supplementation should result in an increase in cell survival. The second approach is the addition of inhibitors which reduce the efficacy of the endogenous defense enzymes. This inhibition should decrease the cell survival after shock wave treatment. The third strategy is the direct measurement of cavitation-generated free radicals, detected as an increase in intracellular oxidation products. By comparing different methods, we were successful in demonstrating cavitation-generated free radicals during shock wave treatment.

L1210 cells incubated with $30 \mathrm{mM}$ cysteamine or cystamine are less sensitive to shock waves than controls without scavengers. The addition of scavenger to the medium increases its osmolarity which results in a shrinkage of the cells and an increase in cytoplasmic viscosity. These changes might influence the sensitivity of the cells to shock waves. An increase in survival rate is always accompanied by a significant shrinkage of the cells, except for $20 \mathrm{mM}$ cystamine. It is impossible, therefore, to distinguish between cell protection by free radical scavenging or by increased cytoplasmic viscosity. Under continuous-wave ultrasound exposure, however, $\mathrm{CHO}$ cells were completely protected from damage by $50 \mathrm{mM}$ cysteamine, while $50 \mathrm{mM}$ cystamine had no effect on cell viability (Armour and Corry 1982). A shrinkage was not reported.

In L1210 cells treated with inhibitors of the endogenous defense enzymes superoxide dismutase and 
catalase, we measured a higher sensitivity of cells to shock waves. It is remarkable, however, that L1210 cells not exposed to shock waves but incubated with the inhibitors diethyldithiocarbamate and aminotriazole had already a reduced viability of less than $50 \%$ of the untreated controls. Furthermore, the incubation of cells with diethyldithiocarbamate and aminotriazole not only specifically reduced the activity of superoxide dismutase and catalase as described by Scott and co-workers (1987) but also unspecifically inhibited carboxyl esterases in L1210 cells. This inhibition frustrated the measurement of cell viability using FDA, a problem which we bypassed by counting the dead cells stained with propidium iodide for the calculation of viable cells. We cannot exclude that such an unspecific enzyme inhibition also causes other reactions than only a reduced antioxidative defense status of the cells.

As the experiments dealing with exogenous supplementation of scavengers and inhibition of endogenous scavenging enzymes were not very conclusive, we performed-as a third strategy-the direct measurement of intracellular free radicals using fluorescent dyes. Because it might be impossible to distinguish between shock wave induced free radicals, directly generated by cavitation, and those that are produced by the respiratory burst of the lymphocytederived L1210 cells stimulated by the debris of cells destroyed by shock waves, these experiments were performed with MGH-U1 cells. These cells also shrunk after incubation with $50 \mathrm{mM}$ cysteamine or cystamine, where the cell diameter was reduced from $16.5 \pm 0.4 \mu \mathrm{m}$ to $14.4 \pm 0.2 \mu \mathrm{m}$ and $13.9 \pm 0.4 \mu \mathrm{m}$, respectively. We, therefore, did not repeat the experiments with scavengers for MGH-U1 cells. To facilitate the direct measurement of intracellular free radicals we decreased the temperature of the lithotripter water bath to $21^{\circ} \mathrm{C}$ thus avoiding a high activity of cellular endogenous defense enzymes without any consequences on the cell's viability.

Hydroethidine-incubated MGH-U 1 cells demonstrated a dose-dependent increase in intracellular fluorescence, indicating an increase in intracellular free radicals but not necessarily intracellular cavitation. This might also be explained by a transient permeabilization of plasma membranes during shock wave treatment. To test whether this is the case, the cells were stained with DCFH-DA and FDA and exposed to shock waves, resulting in a dose and repetition frequency dependent loss of fluorescence due to dye leakage. In our experiments, the dye loss was similar for DCF and fluorescein at $1 \mathrm{~Hz}$, indicating a similar permeability of the cell membrane for both dyes. At a shock wave repetition frequency of $8 \mathrm{~Hz}$, the leakage of fluorescein was increased, whereas DCFH-DA incubated cells exhibited the same decrease in DCFfluorescence as was measured at $1 \mathrm{~Hz}$. Since a dye specific change in membrane permeability at $8 \mathrm{~Hz}$ is not likely, this apparent difference in permeability for fluorescein and DCF must be attributed to the compensation of dye leakage by an increased generation of radical-induced DCF-fluorescence at $8 \mathrm{~Hz}$.

Our results demonstrate an elevated concentration of intracellular free radicals during shock wave treatment of suspended cells in vitro. Free radicals may explain the findings of Russo et al. (1987) and Bräuner et al. (1989) who found histopathologic and ultrastructural damage of cells after shock wave treatment.

Acknowledgements-This work was supported by Bundesministerium für Forschung und Technologie and by Dornier Medizintechnik GmbH. We would like to thank Mrs. B. Rehkopf and Mrs. K. Laskowski for excellent technical assistance.

\section{REFERENCES}

Armour, E. P.; Corry, P. M. Cytotoxic effect of ultrasound in vitro dependence on gas content, frequency, radical scavengers, and attachment. Radiat. Res. 89:369-380; 1982.

Bass, D. A.; Parce, J. W.; Dechatelet, L. R.: Szejda, P.; Seeds, M. C.; Thomas, M. Flow cytometric studies of oxidative product formation by neutrophils: A graded response to membrane stimulation. J. Immunol. 130:1910-1917; 1983.

Bräuner, Th.; Brümmer, F.; Hülser, D. F. Histopathology of shock wave treated tumor cell suspensions and multicell tumor spheroids. Ultrasound Med. Biol. 15:451-460; 1989.

Brenner, J.; Hülser, D. F. A rapid method for the determination of absolute particle sizes in a flow cytometer. In: Schütt, W.; Klinkmann, H.; Lamprecht, I.; Wilson, T. eds. Physical characterization of biological cells: Basic research and clinical relevance. Berlin: Verlag Gesundheit; 1991:131-146.

Brümmer, F.; Brenner, J.; Bräuner, Th.; Hülser, D. F. Effect of shock waves on suspended and immobilized L 1210 cells. Ultrasound Med. Biol. 15:229-239; 1989.

Brümmer, F.; Bräuner, Th.; Hülser, D. F. Biological effects of shock waves. World J. Urol. 8:224-232; 1990a.

Brümmer, F.; Suhr, D.; Hülser, D. F. Do normal and malignant cells differ in their sensitivity to shock waves? J. Endourol. 4(Suppl. 1):S60; 1990b.

Brümmer, F.; Suhr, D.; Hülser, D. F. Standardisierte in-vitro-Modelle zur Charakterisierung von Stoßwellen. Biomed. Tech. 35(Suppl. 3):237-238; 1990c.

Bucana, C.; Saiki, I.; Nayar, R. Uptake and accumulation of the vital dye hydroethidine in neoplastic cells. J. Histochem. Cytochem. 34:1109-1115; 1986.

Burow, S.; Valet, G. Flow-cytometric characterization of stimulation, free radical formation, peroxidase activity and phagocytosis of human granulocytes with 2,7-dichlorofluorescein (DCF). Europ. J. Cell Biol. 43:128-133; 1987.

Coleman, A. J.; Saunders, J. E.; Crum, L. A.; Dyson, M. Acoustic cavitation generated by an extracorporeal shockwave lithotripter. Ultrasound Med. Biol. 13:69-76; 1987.

Coulter, W. H. High speed automatic blood cell counter and cell size analyzer. Proc. Natl. El. Conf. 12:1034-1043; 1956.

Crum, L. A. Cavitation microjets as a contributory mechanism for renal calculi disintegration in ESWL. J. Urol. 140:1587-1590; 1988.

Crum, L. A.; Fowlkes, J. B. Acoustic cavitation generated by microsecond pulses of ultrasound. Nature 319:52-54: 1986 
Delius, M.; Brendel, W. A mechanism of gallstone destruction by extracorporeal shock waves. Naturwissenschaften 75:200-201; 1988.

Delius, M.; Denk, R.; Berding, C.; Liebich, H.-G.; Jordan, M.; Brendel, W. Biological effects of shock waves: Cavitation by shock waves in piglet liver. Ultrasound Med. Biol. 16:467-472; 1990.

Edmonds, P. D.; Sancier, K. M. Evidence for free radical production by ultrasonic cavitation in biological media. Ultrasound Med. Biol. 9:635-639; 1983.

Evans, D. R.; Irwin, R. J.; Havre, P. A.; Bouchard, J. G.; Kato, T.; Prout, G. R. The activity of the pyrimidine biosynthetic pathway in MGH-Ul transitional carcinoma cells grown in tissue culture. J. Urol. 117:712-719; 1977.

Fischer, N.; Muller, H. M.; Gulhan, A.; Sohn, M.; Deutz, F. J. Rubben, H.; Lutzeyer, W. Cavitation effects: Possible cause of tissue injury during extracorporeal shock wave lithotripsy. J. Endourol. 2:215-220; 1988

Flynn, H. G. Generation of transient cavities in liquids by microsecond pulses of ultrasound. J. Acoust. Soc. Am. 72:1926-1932; 1982.

Henglein, A.; Gutiérrez, M.; Ulrich, R. Oxidation of iodide by the intense acoustic bursts of an extracorporeal lithotripter. Int. J. Radiat. Biol. 54:123-126; 1988 .

Hutchison, D. J.; Ittensohn, O. L.; Bjerregaard, M. R. Growth of L1210 mouse leukemia cells in vitro. Exp. Cell Res. 42:157$170 ; 1966$.

Jones, K. H.; Senft, J. A. An improved method to determine cell viability by simultaneous staining with fluorescein diacetatepropidium iodide. J. Histochem. Cytochem. 33:77-79; 1985.

Keston, A. S.; Brandt, R. The fluorometric analysis of ultramicro quantities of hydrogen peroxide. Anal. Biochem. 11:1-5; 1965.

Kuwahara, M. A.; Ioritani, N.; Kambe, K.; Shirai, S.; Taguchi, K.; Saitoh, T.; Orikasa, S.; Takayama, K.; Aida, S.; Iwama, N. Hyperechoic region induced by focused shock waves in vitro and in vivo: Possibility of acoustic cavitation bubbles. J. Lithotripsy \& Stone Dis. 1:282-288; 1990

Law, L. W.; Dunn, T. B.; Boyle, P. J.; Miller, J. H. Observations on the effect of a folic-acid antagonist on transplantable lymphoid leukemias in mice. J. Natl. Cancer Inst. 10:179-192; 1969.

LePecq, J. B.; Paoletti, C. A fluorescent complex between ethidium bromide and nucleic acids. Physical-chemical characterization. J. Mol. Biol. 27:87-106; 1967.
Lingeman, J. E.; McAteer, J. A.; Kempson, S. A.; Evan, A. P. Bioeffects of extracorporeal shock-wave lithotripsy. Strategy for research and treatment. Urol. Clin. North Am. 15:507-514; 1988.

Makino, K.; Mossoba, M. M.; Riesz, P. Formation of $\cdot \mathrm{OH}$ and $\cdot \mathrm{H}$ in aqueous solutions by ultrasound using clinical equipment. Radiat. Res. 96:416-421; 1983.

Masters, J. R. W.; Hepburn, P. J.; Walker, L.; Highman, W. J. Trejdosiewicz, L. K.; Povey, S.; Parkar, M.; Hill, B. T.; Ridde, P. R.; Franks, L. M. Tissue culture model of transitional cell carcinoma: Characterization of twenty-two human urothelial cell lines. Cancer Res. 46:3630-3636; 1986.

Morgan, T. R.; Laudone, V. P.; Heston, W. D. W.; Zeitz, L.; Fair, W. R. Free radical production by high energy shock waves-Comparison with ionizing irradiation. J. Urol. $139: 186-189 ; 1988$

Révész, L.; Bergstrand, H. Radiation protection by cysteamine and cellular sulphydryl levels. Nature 200:594-595; 1963.

Riedlinger, R.; Ueberle, F.; Zanger, U. HEPUS (High energy pulsed ultrasound): Apparatus and physical aspects of tumor-insonification. Biomed. Technik 33 (Suppl. 2):139-140; 1988.

Rothe, G.; Valet, G. Flow cytometric analysis of respiratory burst activity in phagocytes with hydroethidine and $2^{\prime}, 7^{\prime}$-dichlorofluorescin. J. Leukocyte Biol. 47:440-448; 1990.

Russo, P.; Stephenson, A.; Mies, C.; Huryk, R.; Heston, W. D.; Melamed, M. R.; Fair, W. R. High energy shock waves suppress tumor growth in vitro and in vivo. J. Urol. 135:626-628; 1986.

Russo, P.; Mies, C.; Huryk, R.; Heston, W. D. W.; Fair, W. R. Histopathologic and ultrastructural correlates of tumor growth suppression by high energy shock waves. J. Urol. 137:338-341; 1987.

Sawada, S.; Okada, S. Cysteamine, cystamine, and single-strand breaks of DNA in cultured mammalian cells. Radiat. Res. 44:116-132; 1970

Scott, J. A.; Khaw, B. A.; Homcy, C. J.; Rabito, C. A. Oxygen radicals alter the cell membrane potential in a renal cell line (LLC-PK 1) with differentiated characteristics of proximal tubular cells. Biochim. Biophys. Acta 897:25-32; 1987.

Thomas, G.; Roques, B. Proton magnetic resonance studies of ethidium bromide and its sodium borohydride reduced derivative. FEBS Lett. 26:169-175; 1972 .

Williams, A. R.; Delius, M.; Miller, D. L.; Schwarze. W. Investigation of cavitation in flowing media by lithotripter shock waves both in vitro and in vivo. Ultrasound Med. Biol. 15:53-60; 1989. 